\title{
The Road to Universal Health Coverage in Myanmar Runs through Non-Communicable Disease Risk Factors: Supporting Evidence from WHO in 2009 and 2014 and the Global Burden of Disease Study 2016
}

\author{
Khin Thiri Maung1 (), Paul Kowal1,2,3 (), Nawi Ng4,5 (), Tej Ram Jat1 ${ }^{(0)}$ \\ ${ }^{1}$ HelpAge International, Yangon, Myanmar \\ ${ }^{2}$ Research Institute for Health Sciences, Chiang Mai University, Chiang Mai, Thailand \\ ${ }^{3}$ WHO Study on Global Ageing and Adult Health (SAGE), World Health Organization, Geneva, Switzerland \\ ${ }^{4}$ Department of Public Health and Clinical Medicine, Umeå University, Umeå, Sweden \\ ${ }^{5}$ Centre for Demographic and Aging Research, Umeå University, Umeå, Sweden \\ Email: khin.thiri@helpagemyanmar.org
}

How to cite this paper: Khin Thiri Maung, Paul Kowal, Nawi Ng, Tej Ram Jat (2019) The Road to Universal Health Coverage in Myanmar Runs through Non-Communicable Disease Risk Factors: Supporting Evidence from WHO in 2009 and 2014 and the Global Burden of Disease Study 2016. Health, 11, 1206-1223.

https://doi.org/10.4236/health.2019.119094

Received: May 5, 2019

Accepted: September 26, 2019

Published: September 29, 2019

Copyright $\odot 2019$ by author(s) and Scientific Research Publishing Inc. This work is licensed under the Creative Commons Attribution International License (CC BY 4.0).

http://creativecommons.org/licenses/by/4.0/

\begin{abstract}
Background: The recent surge in economic development in Myanmar will also contribute to accelerating the health burden shift from acute infectious to chronic non-communicable diseases (NCDs) across the country. With just 11 years to achieve its goal of universal health coverage by the year 2030, significant efforts will be needed to quantify the scale of the burden facing decision-makers about health system strengthening and redevelopment. Convergence of the health systems will be an additional challenge in Myanmar. Methods: Results from a WHO study in 2009 and 2014, combined with data from the 2016 Global Burden of Disease Study, were compiled and analysed for Myanmar to assess the levels and trends of selected NCDs and NCD risk factors. Results: The prevalence of major NCDs in Myanmar are in general higher than global and regional averages, with a significant increase in diabetes mellitus and chronic obstructive pulmonary diseases in the last 25 years. Major NCD risk factors in Myanmar include smoking, use of smokeless tobacco, alcohol consumption among men, low level of fruit and vegetable consumption, hypertension, and emerging of overweight and obesity, especially among women. Tobacco use increased in both sexes between 2009 and 2014, but only significantly in men. Rates of hypertension increased for both men and women, including those currently on medications-suggesting a need for better treatment regimens. Overweight and obesity rates increased
\end{abstract}


in both men and women, although the increase in obesity for men was not significant. Alcohol consumption results were mixed-with lower levels of high level drinking in men, but generally increased consumption by women. Intake of fruit and vegetables increased slightly between 2009 and 2014 and rates of high levels of physical activity also increased. Diabetes prevalence rates increased significantly in women $\left(\mathrm{X}^{2}=11.3 ; \mathrm{p}=0.01\right)$ and men $\left(\mathrm{X}^{2}=\right.$ 9.6; $p=0.02$ ) between 2009 and 2014. Conclusions: Improved awareness of risk factors, coupled with early diagnosis and effective treatment of conditions and risks, is paramount to keeping the population healthy and economically active, and maintaining health care costs. Proven cost-effective interventions to prevent and control NCD-related risk factors, notably increasing tobacco taxes, should be endorsed and implemented in the population. Inaction could hamper the country's effort to achieve universal health coverage by the year 2030 .

\section{Keywords}

Noncommunicable Disease, Prevalence, Risk Factors, Surveillance, Diabetes, Universal Health Coverage, Myanmar

\section{Introduction}

Myanmar has set a goal of achieving universal health coverage by the year 2030 [1]. As a result, health and social systems will need to account for the ongoing demographic and epidemiological shifts [2]. Perhaps the most significant evolving demographic trend is the ageing of populations: Myanmar, like most of the rest of the world, is ageing. Myanmar's 2015 population included an estimated 4.7 million people aged 60 -plus years ( $8.9 \%$ of the population) across the country, with projections reaching 11.5 million (18.5\% of the population) by 2050 [3]. Projections from these data reveal a similar number of people aged 0 - 14 years as those aged 60 years and older by the year 2050, which would represent a demographic milestone. Meanwhile, a bulge of adolescents will move through the population structure, so that by the year 2050, the demographic pyramid will instead have a honeypot shape (see Figure 1). These demographic projections provide concrete evidence of the increasing numbers and proportion of older adults in the total population-which in turn is a considerable contributing force in the unfolding population health transition.

In parallel, the population of Myanmar is experiencing an ongoing and rapid health transition, with the persistent burden from communicable diseases, but high and increasing impacts from chronic conditions and injuries [4] [5] [6]. Communicable diseases like tuberculosis and dengue cause considerable morbidity and mortality-yet chronic conditions like diabetes and cardiovascular disease are already the biggest burdens. The most current estimates for the attribution of causes of death indicate $72 \%$ are from NCDs compared to $19 \%$ from communicable diseases (Table 1). 

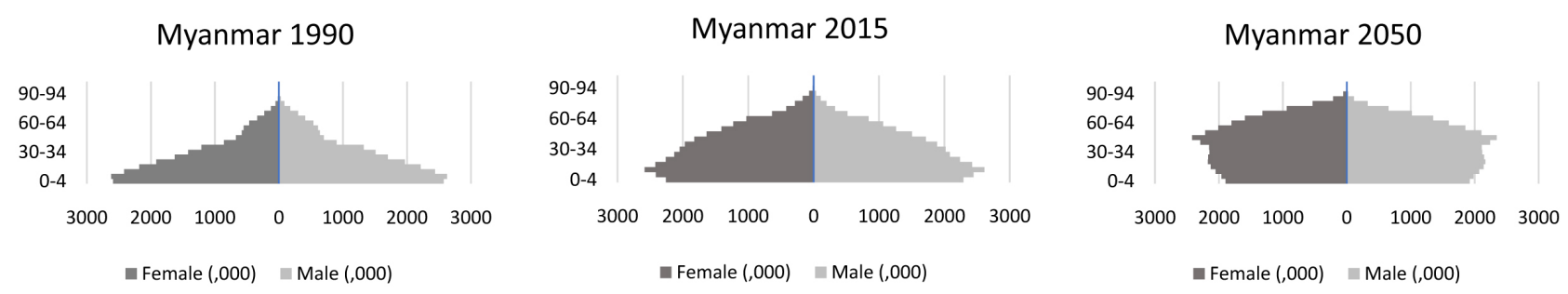

Figure 1. Population pyramids for 1990, 2015 and 2050, Myanmar. Source: UN Population Division. World Population Prospects: The 2017 Revision. New York: United Nations; 2017.

Table 1. Percent (\%) composition of burden of disease measures, death, DALYs and YLD, by major disease groupings, for 1990 and 2016 (sexes combined).

\begin{tabular}{ccccccc}
\hline \multicolumn{3}{c}{1990} & \multicolumn{3}{c}{2016} \\
\hline \multicolumn{1}{c}{ Deaths (\%) DALYs (\%) YLD (\%) Deaths (\%) DALYs (\%) } & YLD (\%) \\
\hline $\begin{array}{c}\text { Communicable, maternal, } \\
\text { neonatal, and nutritional diseases }\end{array}$ & 46.8 & 57.0 & 25.5 & 19.2 & 25.5 & 13.3 \\
Non-communicable disease & 46.4 & 35.9 & 70.6 & 72.4 & 64.7 & 80.8 \\
Injuries & 6.8 & 7.1 & 3.9 & 8.4 & 9.8 & 5.9 \\
\hline
\end{tabular}

*DALYs (Disability Adjusted Life Years); YLD (Years of Life lived with Disability). Source: GBD 2016, IHME 2017b.

Compared to 1990, the 2016 results show a large shift towards higher impact on overall burden from NCD-related deaths (Table 1). Increasing morbidity (DALY from $36 \%$ to $65 \%$ ) and disability (YLD, from $71 \%$ to $81 \%$ ) from NCDs was seen between 1990 and 2016. The combination of these factors, coupled with declining fertility rates in the country, shape the current trends in population health-such as life expectancy (LE) and healthy life expectancy (HALE). Life expectancy is the average number of years one is expected to live, while HALE is the expected number of year years of life in good health. Women outlive men on average in most countries in the world, yet both sexes are faced with a question about the level of health in the extra years of life lived. On average, women live longer despite having higher levels of morbidity and disability and this is also the case in Myanmar. An example here of life expectancy at older ages (60 - 64, 65 - 69, 70 - 74 and 75 - 79) in women in Myanmar shows gains in both LE and HALE but comparing the two charts by year shows larger gains in LE than HALE between 1990 and 2016 at each age group (Figure 2). This suggests a longer time spent in state of poor health with increasing longevity, that is, an expansion of morbidity.

Situating Myanmar within the context of other Asian countries, an examination of the different drivers of change in life expectancy at birth for males and females are delineated in Figure 3, with clear differences in the changes in life expectancy and healthy life expectancy between 1990 and 2016. Males and females gained considerable years in Myanmar between 1990 and 2015, particularly in the last five years, but with the health improvements behind the gains in Myanmar looking more similar to the patterns seen in neighbouring Lao PDR 
25

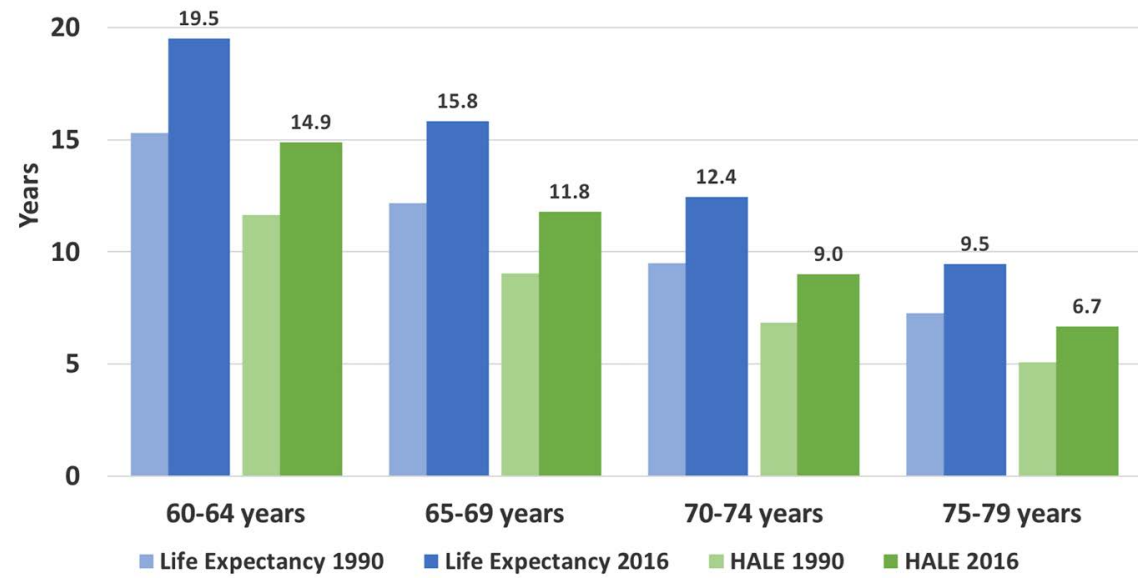

Figure 2. Life expectancy and healthy life expectancy at older ages (mean in years) in women aged 60 - 79 years, Myanmar, 1990 and 2016.

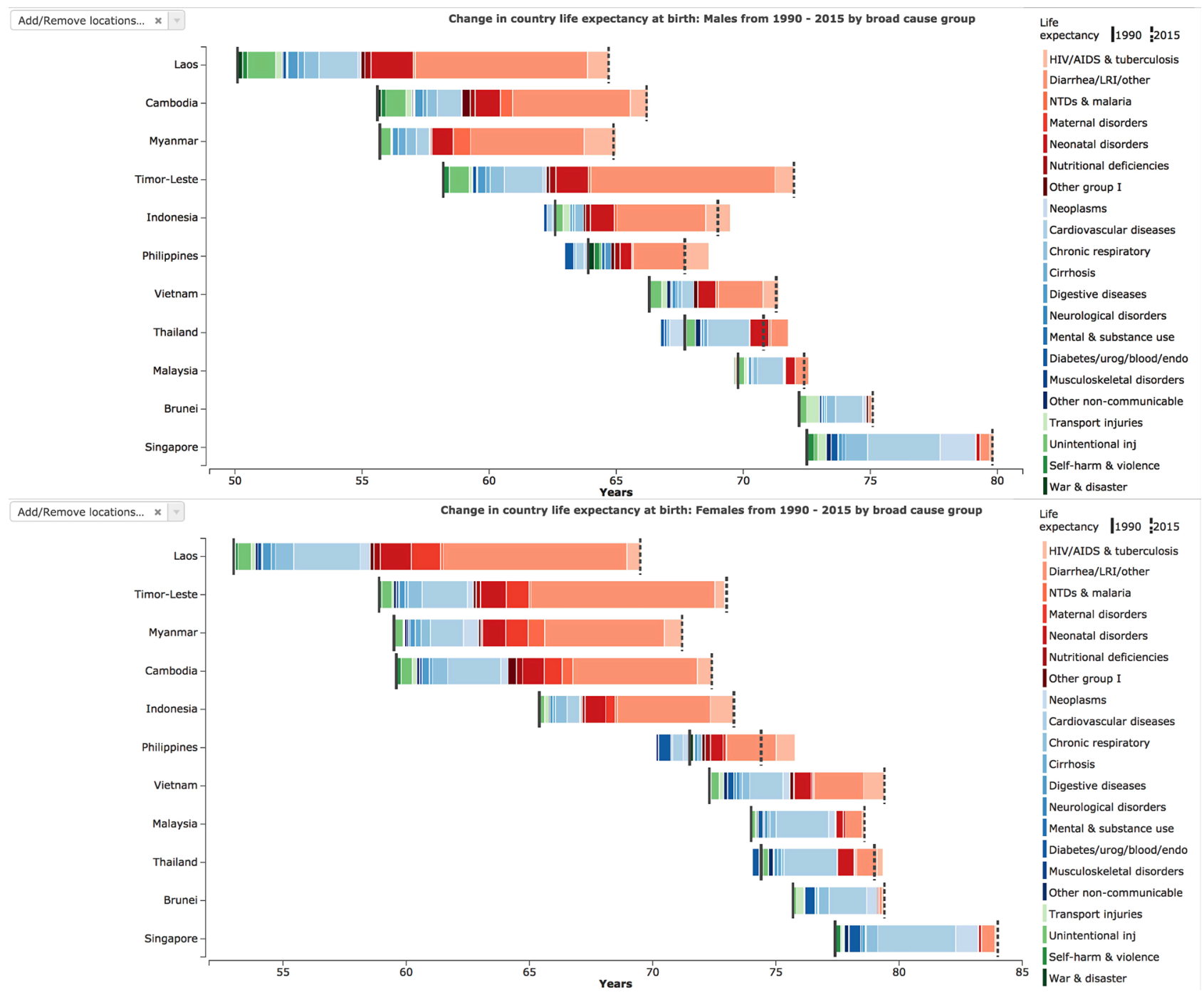

Figure 3. Changes in life expectancy at birth among men and women in 11 Southeast Asian countries during 1990-2015. 
and Cambodia, than higher income countries like Thailand or Viet Nam (Figure 3). While LE increased 19.5 years among women aged 60 - 64 years, HALE increased only 14.9 years in the same period. The gaps are much smaller among the older women, for example about 2.8 years only among women aged $75-79$ years. Reductions in infectious diseases contributed comparatively more to the gains in LE for males and females in Myanmar, than NCDs. However, this belies the potential gains from treating NCDs, given the high proportion of burden for this group of health conditions.

Given the large and growing burden from NCDs in Myanmar, and its likely impact on population health outcomes, health and social systems should be looking at the factors that influence the course and severity of these conditions. In 2011, the United Nations adopted a political declaration for the prevention and control of NCDs, where action plans were adopted in a second meeting in 2014, and with a third meeting planned for 2018 [7]. The follow-on agreements included targets to reduce a set of health risks that have been shown to be amenable to interventions. The relationships between NCDs and health risks, such as low physical activity, poor diet and tobacco consumption, are constantly evolving and differ by population and setting, yet a consistent finding is that many NCD risks are modifiable-even into older ages. Diet and high salt intake, smoking, sedentary lifestyle, and harmful alcohol consumption all influence the risk developing an NCD and of dying from it. Given that the risks can be modified, they have been targeted by "best buy" strategies to address NCDs [8].

Until recently, relevant health data in Myanmar on NCDs and related risk factors were limited. The World Health Organization's STEP wise approach to noncommunicable disease risk factor surveillance (WHO STEPS) surveys, completed in 2009 and 2014, provide recent sequential cross-sectional data on the levels of health risks and a high burden condition (diabetes) from across the country [9] [10]. Results from these two studies were assessed, in the context of data from the 2016 Global Burden of Disease (GBD) Study, to examine the levels and trends of selected NCDs and NCD risk factors. This paper presents an examination of the current situation of NCDs and impacts of common NCD risk factors in adult populations based on the most current information available in Myanmar.

\section{Methods}

This paper is based on secondary data Analysis. Data on NCD risk factors were derived from two cross-sectional national-level household surveys implemented in 2009 and 2014 in Myanmar, both of which used a standarized methodology [9] [10]. Additional data from the GBD Study 2016 was analysed and included for contextual purposes. The surveys covered three levels of assessment, including a questionnaire, physical measurements, and biochemical measurements. Multistage cluster sampling methods and a stratified sampling strategy with four diverse ecological regions-hilly, central plain, coastal and delta, was used to select nationally representative cohorts in both study years. The final sample for 
the 2009 study was $n=7429$ community-dwelling persons aged 15 - 64 years [11]. Importantly, given the high burden from tobacco, a number of questions from the Global Adult Tobacco Study were added to the standard questionnaire [12]. This 2019 Study included a survey and physical measurements, but not biomarkers.

The 2014 sample included $\mathrm{n}=8757$ community-dwelling adults aged 25 - 64 years [13]. To achieve a nationally representative sample, a multi-stage sampling method was used to select townships, wards and villages, households and eligible participants at each of the selected households. Administratively, Myanmar is divided into 330 townships. A township is subdivided into wards for urban settings and village tracts and then villages for rural settings. The list of townships has been used as the sampling frame at the first stage of sampling. Out of the total 330 Primary Sampling Units (PSUs), 52 PSUs were selected using Probability Proportionate to Size of population in each PSU. From each selected PSUs (township), 6 Secondary Sampling Units (wards and villages) were be chosen using probability proportionate to population size, totalling 312 SSUs for the whole country. Each PSU (township) was estimated to contribute 180 participants, totalling 9360 participants for 52 selected townships for the whole country. Interviews and physical measurements were conducted in respondent households, with biomarkers collected at a centralized location. The questionnaire for 2014 was based on the 2009 instrument.

Current user of tobacco was defined as anyone who currently smoked and used any smokeless tobacco product. Current drinker was anyone who consumed alcohol in the past 30 days (beer, wine, spirits, fermented toddy palm sac or Khaung-yay). High-level drinking is defined as 60 grams or more of pure alcohol per occasion for men or 40 grams for women. Low levels of fruit and vegetable consumption are considered eating less than 5 servings (about 400 grams) per day. Physical activity was categorized into high, moderate and low levels based on estimates of the working to resting metabolic rate (METs) [14]. Physical activity includes recreational or leisure-time physical activity, transportation (walking or cycling), occupation-related, household chores, play, games, sports or planned exercise, in the context of daily family, and community activities. Blood pressure measurements used hypertension defined as systolic blood pressure $\geq 140 \mathrm{mmHg}$ and/or diastolic blood pressure $\geq 90 \mathrm{mmHg}$. Raised blood pressure results were reported separately for excluding and including medications to control blood pressure. Body mass index (BMI) was calculated from measured height and weight, with underweight being categorized as $<18.5$, normal 18.5 - 24.9, overweight 25.0 - 29.9 and obese 30 or higher [15].

Descriptive analyses were undertaken to compare results from the two waves of data collection. Chi-square tests were used to determine whether significant differences in risk prevalence were present comparing the 2009 and 2014 results.

Results for Myanmar from the Global Burden of Disease (GBD) 2016 Study were analysed for a selection of chronic conditions related to the key risk factor results from the 2009 and 2014 surveys. These conditions included myocardial 
infarction, stroke, diabetes and chronic obstructive pulmonary disease. To put these results into context, the Myanmar results were also plotted against the regional and global GBD 2016 averages [16].

\section{Results}

Both years of data collection included more women than men (61\% in 2009 and $65 \%$ in 2014), with a lower mean number of years of education in the 2014 cohort compared to the 2009 cohort (see supplementary tables). Women had a lower mean number of years of education than men in both cohorts. Marital status was similar across the two study years.

\subsection{Tobacco Use}

In $2009,74 \%$ of male and $21 \%$ of female respondents reported currently using smoked, smokeless or both forms of tobacco. Current tobacco use increased for both men (80\%) and women (29\%) in the 2014 survey: the difference between survey years was significant in men $\left(\mathrm{X}^{2}=16.9 ; \mathrm{p}=0.001\right)$ but not significant in women $\left(\mathrm{X}^{2}=6.3 ; \mathrm{p}=0.10\right)$. The breakdown by type of tobacco use, sex and age group for both cohorts is included in Figure 4.

\subsection{Alcohol and Diet}

The level of current drinkers was higher in the age groups from 25 - 54 years in 2014 compared to 2009 (Figure 4), yet overall, the differences in current drinkers were not significant in men $\left(X^{2}=5.6 ; p=0.14\right)$ or women $\left(X^{2}=2.1 ; p=0.56\right)$ when comparing 2009 to 2014 . However, the rates of high-level drinking were lower for men in 2014 compared to 2009, and higher for women in all age groups except women aged 35 - 44 (both years with no high-level drinking) (data not shown).

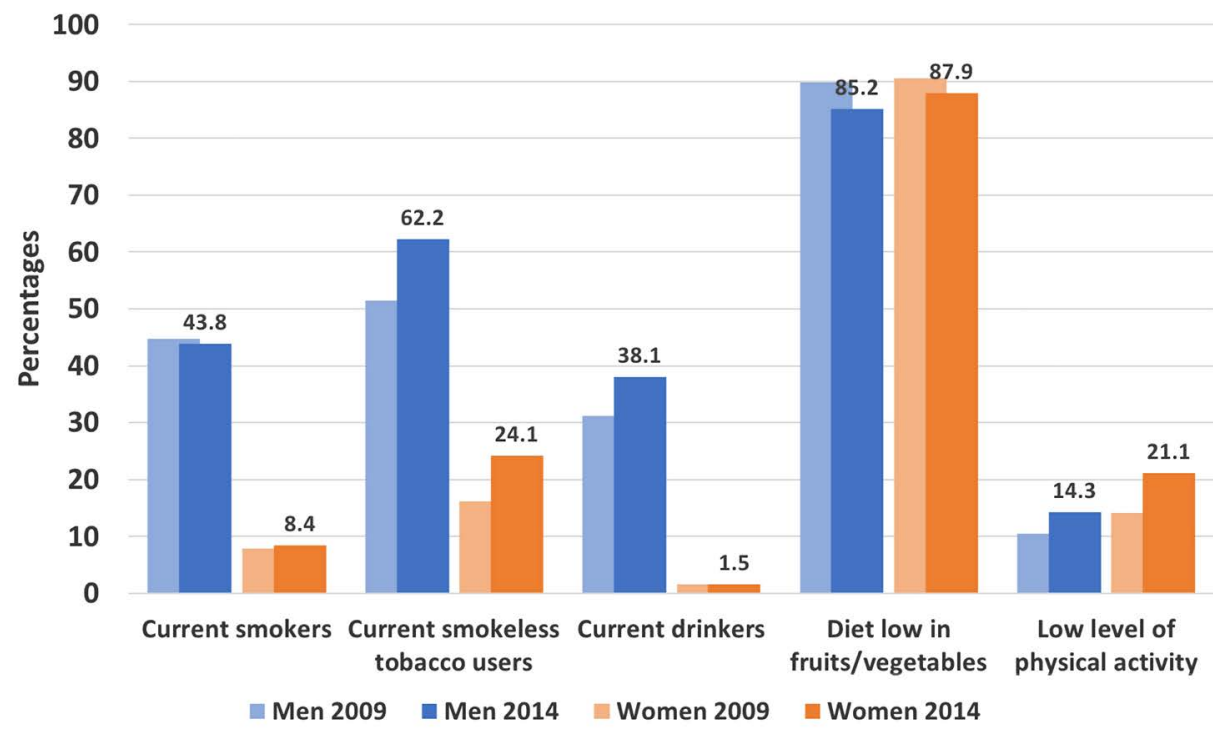

Figure 4. Prevalence of behavioural risk factors among the adult population in Myanmar. 
Low percentages of both females and males consumed sufficient fruit and vegetables on a daily basis. About $90 \%$ of both sexes did not eat the recommended five daily servings of fruit and/or vegetables in 2009, this improved slightly in 2014 , albeit statistically significant, with $88 \%$ of females $\left(X^{2}=46.5 ; \mathrm{p}<\right.$ $0.001)$ and $85 \%$ of males $\left(\mathrm{X}^{2}=12.4 ; \mathrm{p}=0.006\right)$ with a low consumption diet.

\subsection{Physical Activity}

A comparatively smaller percentage of respondents in each age group had low levels of reported physical activity with non-significant changes over the five years between the two studies (females, $\mathrm{X}^{2}=7.1, \mathrm{p}=0.07$; males, $\mathrm{X}^{2}=4.5, \mathrm{p}=$ $0.21)$. A significantly lower number of females $\left(X^{2}=35.2 ; \mathrm{p}<0.001\right)$ and males $\left(\mathrm{X}^{2}=22.2 ; \mathrm{p}<0.001\right)$ engaged in moderate level physical activity, whereas a significantly higher number of females $\left(\mathrm{X}^{2}=21.7 ; \mathrm{p}<0.001\right)$ and males $\left(\mathrm{X}^{2}=\right.$ 9.1; $\mathrm{p}=0.03)$ reported high levels of physical activity, when comparing 2009 to 2014 results.

\subsection{Blood Pressure}

Levels of hypertension were higher in females and males in 2014 compared to 2009 , for those who are not on medication as well as respondents treated with medications (Figure 5). The differences in hypertension in 2009 and 2014 were significant for females $\left(\mathrm{X}^{2}=15.8 ; \mathrm{p}=0.001\right)$ and males $\left(\mathrm{X}^{2}=17.0 ; \mathrm{p}=0.001\right)$ not on medications, as well as females $\left(\mathrm{X}^{2}=15.8 ; \mathrm{p}=0.001\right)$ and males $\left(\mathrm{X}^{2}=15.0\right.$; $\mathrm{p}=0.002)$ currently on medications.

\subsection{Body Mass Index (BMI)}

The levels of underweight were higher in 2014 than 2009, but while it was not significantly different for females $\left(\mathrm{X}^{2}=7.1 ; \mathrm{p}=0.07\right)$, it was significant in males $\left(\mathrm{X}^{2}=12.7 ; \mathrm{p}=0.001\right)$ (Figure 5). Levels of overweight in both sexes, and obesity in women $\left(\mathrm{X}^{2}=12.3 ; \mathrm{p}=0.007\right)$ increased significantly between 2009 and 2014, but obesity levels did not increase significantly for men $\left(X^{2}=1.5 ; \mathrm{p}=0.686\right)$.

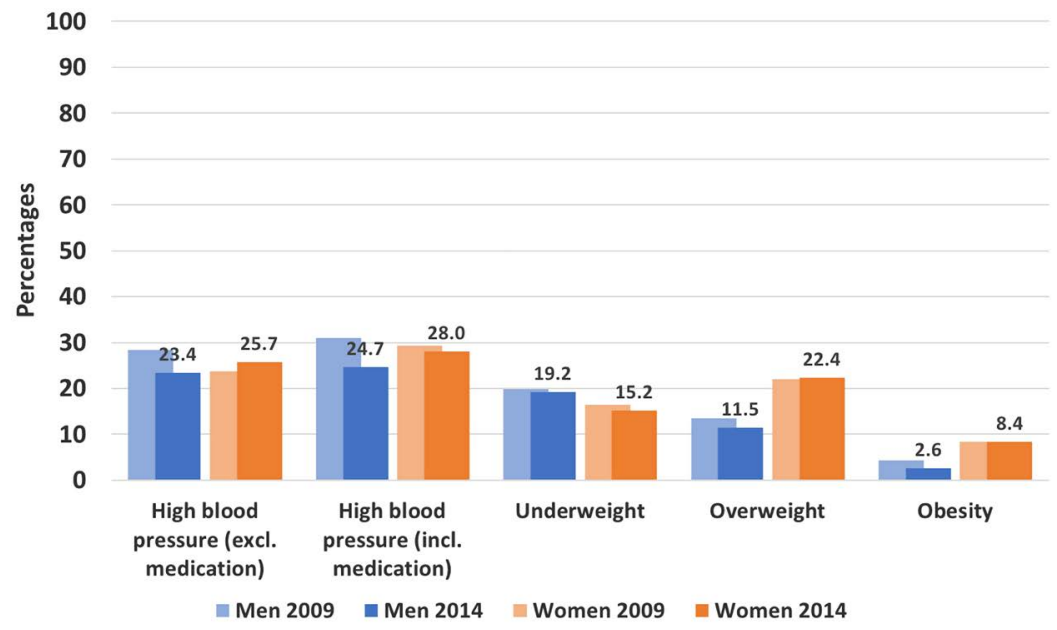

Figure 5. Prevalence of biological risk factors among the adult population in Myanmar. 


\subsection{Chronic Conditions Impacted by These Risk Factors \\ Diabetes}

The scourge of diabetes increased significantly between 2009 and 2014 in both women $\left(X^{2}=11.3 ; \mathrm{p}=0.01\right)$ and men $\left(\mathrm{X}^{2}=9.6 ; \mathrm{p}=0.02\right)$ - with much higher prevalence in women than men in 2014 (Figure 6). The percentage of younger women getting tested was lower in 2009 than 2014, but the opposite for older women. The pattern was less positive for men, with higher levels of men who reported never having their blood tested in 2014 compared to 2009.

Figure 7 also plots the prevalence of diabetes from GBD 2016 for men and women in Myanmar, the region, and globally for 2016, along with three other conditions (myocardial infarction (MI), haemorrhagic stroke and chronic obstructive pulmonary disease (COPD)) impacted by a largely common set of risk factors. According to these results, the men have lower rates compared to women in Myanmar until older ages, when the rates are more similar between the sexes. The prevalence of diabetes for men in Myanmar might be slightly higher than the global average between the ages of 20 to 40 years, while slightly lower for men aged 80 years and older. For women in Myanmar, the rates are in line with global average, but slightly lower than the regional average for women aged 40 and older. The prevalence of the other three conditions is generally consistent with the regional averages, but higher than global averages in 2016, particularly for COPD.

Looking at the patterns of prevalence rates of the same four conditions from 1990 to 2015 in Figure 8, suggest lower prevalence of diabetes in Myanmar compared to the region for women over the entire time period, but with men's rates reaching and exceeding the average regional rates during this period. Except for MI in women, the rates of the other three conditions are also generally higher than the regional and global averages-again, with COPD being a standout for poor health.

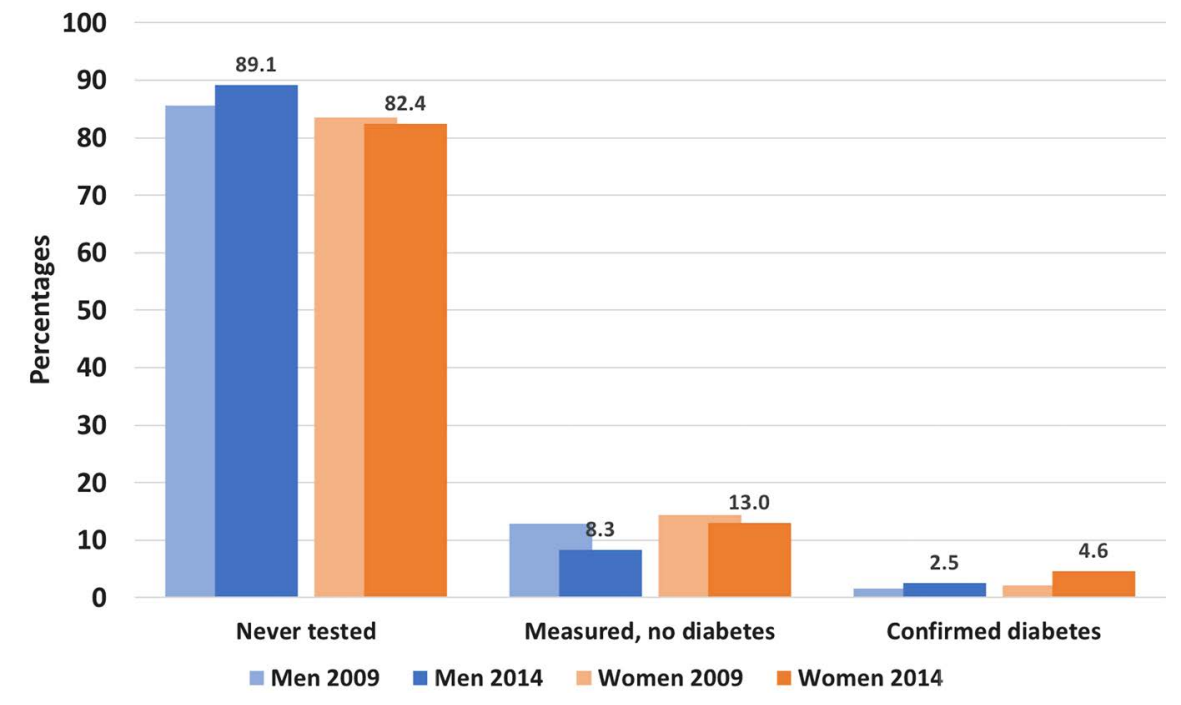

Figure 6. Diabetes measurement and diagnosis among the adult population in Myanmar. 
MYOCARDIAL INFARCTION DUE TO ISCHAEMIC HEART DISEASES
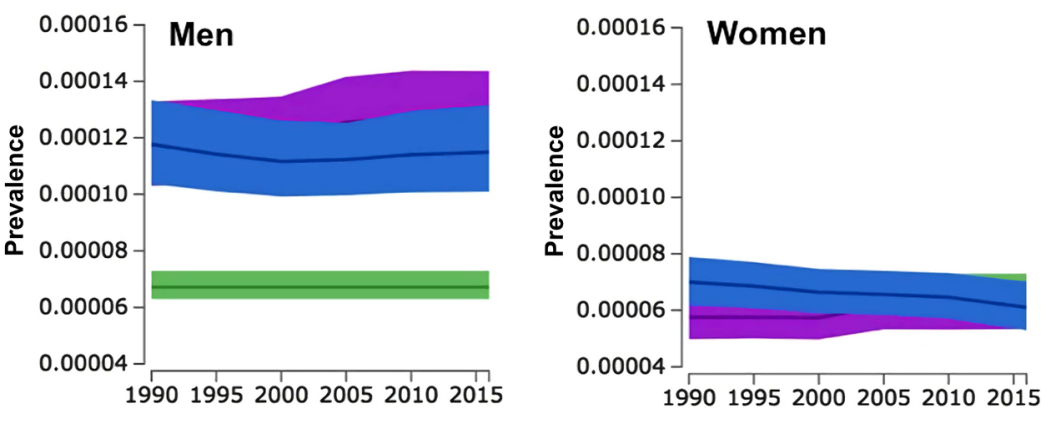

FIRST EVER ACUTE HAEMORRHAGIC STROKE
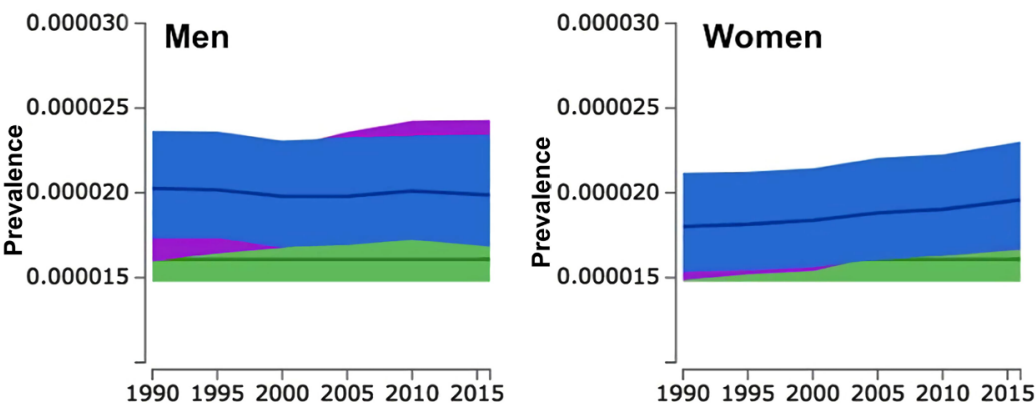

DIABETES MELLITUS
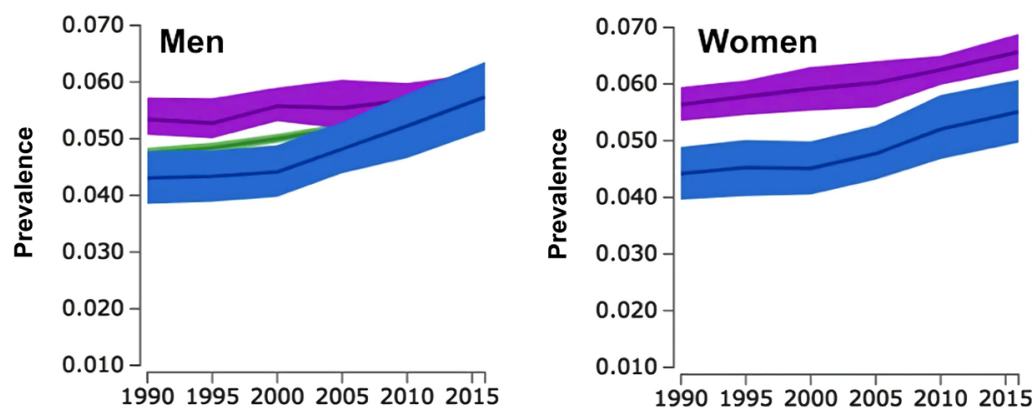

CHRONIC OBSTRUCTIVE PULMONARY DISEASES
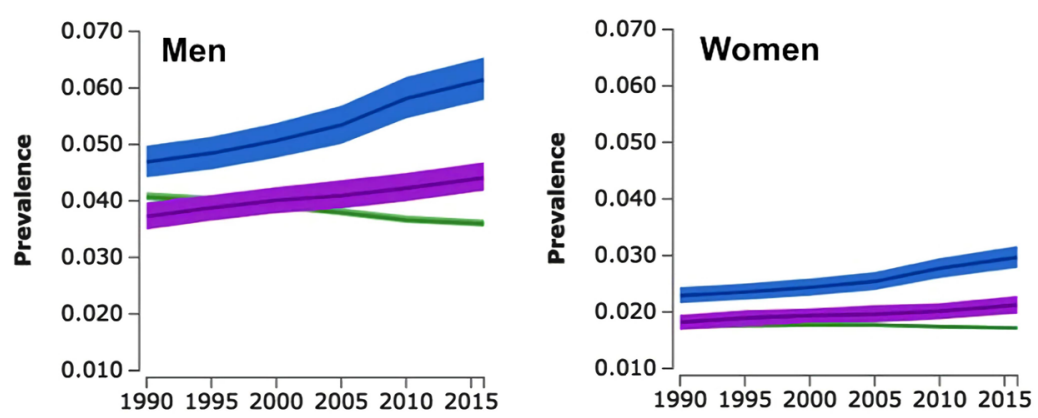

Figure 7. Trends in the age-standardized prevalence of select chronic diseases in Myanmar (blue) compared to those in the region (purple) and global (green) between 1990 and 2015, with 95\% confidence intervals (source: IHME 2017).

\section{Discussion}

Household surveys are an essential source of information as the government progressively moves towards achieving universal health coverage by the target 

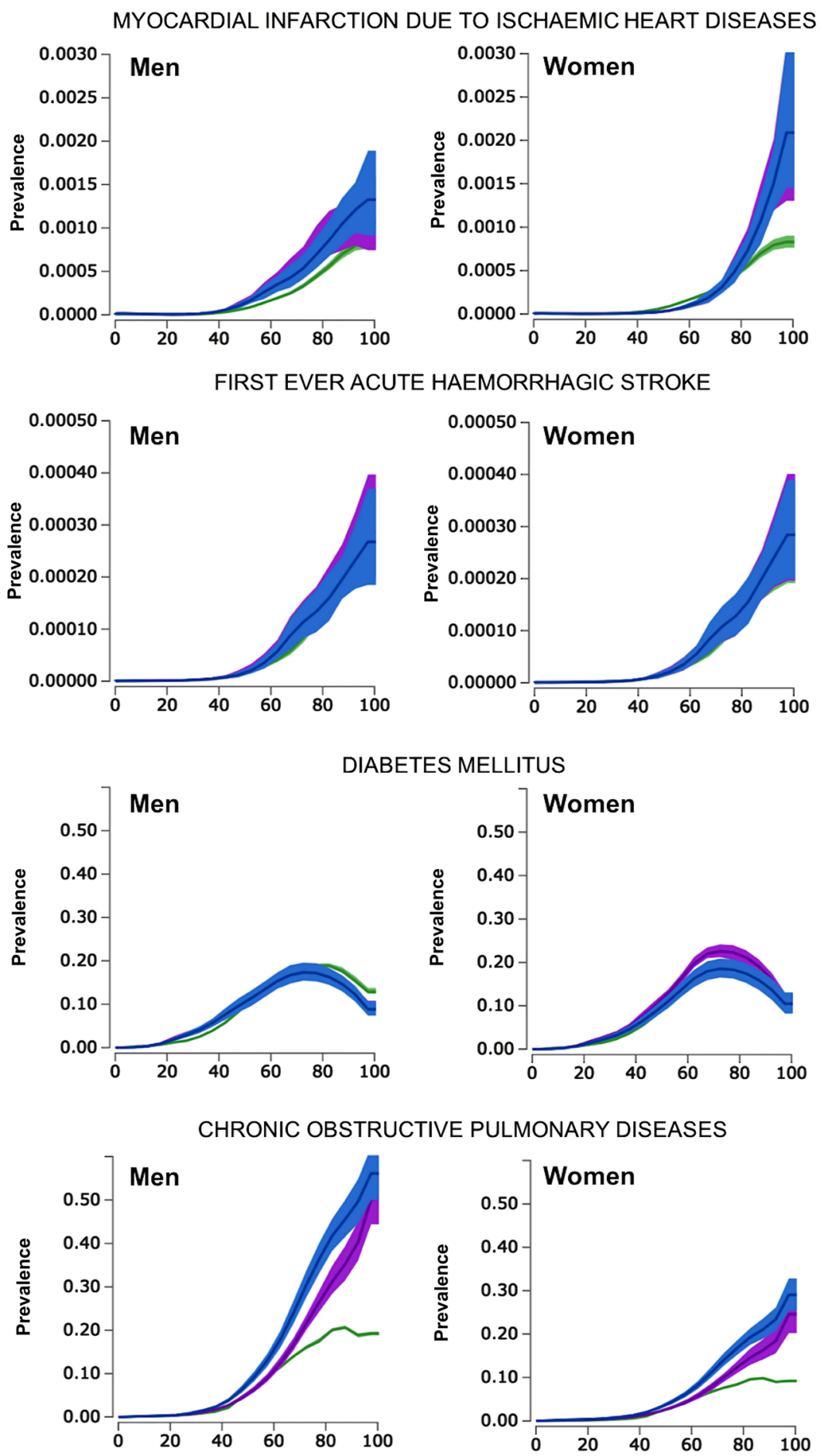

Figure 8. Age-standardized prevalence of select chronic diseases across different age groups in Myanmar (blue) compared to those in the region (purple) and global (green) in 2016, for men and women, with 95\% confidence intervals (source: IHME 2017).

date of 2030 [17]. The results of two large studies implemented in Myanmar in $2009(\mathrm{n}=7429)$ and $2014(\mathrm{n}=8757)$ show high and increasing levels of most non-communicable disease risk factors and diabetes in women and men. With a few exceptions, the levels of most health risks increased for women and men, 
and across all age groups when comparing 2009 to 2014 results. These results suggest the need for action across a number of sectors, at the individual, community and government levels. Noting these results, the need for risk factor reduction as a key outcome in the framework for monitoring health sector progress and performance will be essential (see Figure 1) [18].

The level of diabetes in Myanmar increased between 2009 and 2014, and is higher than the mean for countries at a similar level of development in the region, including Cambodia, although not as high as Lao PDR, for example [6]. While diabetes rates in Myanmar are lower than the high-income countries in the region, the total DALYs that diabetes contributed to overall disease burden in the country increased by almost $40 \%$ between 2005 and 2016, with high blood glucose remaining sixth in the ranking of risk factors driving death and disability [16]. The World Economic Forum estimates that 8.5 million people die from the complications of NCDs in Asia annually [19], with Myanmar currently at the second lowest life expectancy amongst ASEAN nations after Lao PDR [20]. Per capita spending on health is the third lowest in Myanmar, following only Cambodia and Lao PDR amongst this cohort of countries [21]. Luckily, efforts within the country to train clinicians and other health care professionals and para-professionals to look after diabetes and other NCDs have made tremendous progress over the past three years with leadership from the University of Public Health, University of Medicine 2 and HelpAge International Myanmar [22]. This has the potential to shift care practices in government run health care facilities across the country.

These national results are complemented by results from the 2016 Global Burden of Disease Study, further suggesting the downstream impacts that high risk levels are having on population health in Myanmar. The GBD 2016 data also help to put these results in context in the region and globally (see again, Figure 7 and Figure 8). Myanmar's NCD situation is mixed in terms of how it compares to regional levels-higher burden of chronic pulmonary diseases and myocardial infarction at older ages, possibly lower burden from diabetes than the regional average and similar levels of stroke. Regardless of the current prevalence rates, without concentrated efforts to shift the high and increasing levels of key NCD risk factors like tobacco use and hypertension in the country, future burden on health care systems can only increase. Efforts to achieve universal health coverage in Myanmar by 2030 will require a comprehensive understanding of the main burdens facing the health system. In addition to educational public health preventive measures that address risk factors like tobacco, alcohol, diet and physical activity, other levers, like salt or sugar taxes, should be considered to slow the rising tide of NCDs. Equally, improvements in the education system and the 2018 increase in minimum wage work to address the social determinants - the root causes of some of these key factors impacting health.

Population ageing in Myanmar is important because of the current and future effects on the economic development of the country. Beyond their continued contributions to the workforce into older age, family support structures rely 
heavily on older adults to care for grandchildren, thereby allowing their adult children to maximize their financial utility [23] [24]. This makes reaching older ages in a state of good health important for both direct and indirect contributions to families and societies.

\section{Strengths and Limitations}

These studies used standardized methods and instruments in each of the two years the data were collected and included a large sample of respondents across most regions in the country. The studies are cross-sectional and therefore, the results are limited to reporting associations. Access to the original WHO STEPS Myanmar data was not granted, however, the re-examination of published results included here are robust and were supplemented with the most recent Global Burden of Disease Study data.

\section{Conclusion}

The rapid demographic transition in Myanmar in the last 25 years has led to epidemiological transition in the country, with chronic NCDs account for three quarters of all deaths among adult population in 2016. Though the population is living longer, a longer time is spent in state of poor health, that is, an expansion of morbidity. The prevalence of major NCDs in Myanmar is in general higher than the global estimates, with a significant increase in diabetes mellitus and chronic obstructive pulmonary diseases in the last 25 years. Major NCD risk factors in Myanmar include smoking, use of smokeless tobacco, alcohol consumption among men, low level of fruit and vegetable consumption, hypertension, and emerging of overweight and obesity, especially among women. Routine monitoring of risk factor level is essential in tracking the progress to control NCD risk factors in the population. Prevention and control of NCDs can be achieved through cost-effective interventions towards reducing the risk factors burden in the population, which can prevent NCD-related disability and premature deaths. Inaction can hamper the country's effort to achieve universal health care by the year 2030 .

\section{Acknowledgements}

This study was funded by HelpAge International Myanmar under their "strengthening public health capacity to respond to Myanmar's disease transition" project supported by European Union under grant number DCI-SANTE/2014/342-298. The views expressed in this article are solely those of the authors and do not necessarily represent the official positions of the organizations the authors are affiliated with.

\section{Conflicts of Interest}

The authors declare no conflicts of interest regarding the publication of this paper. 


\section{References}

[1] Ministry of Health and Sport (2017) National Health Plan 2017-2021. Ministry of Health and Sport, Nay Pyi Taw.

https://themimu.info/sites/themimu.info/files/assessment_file_attachments/NHP_2 017-2021_ENG_0.pdf

[2] Boerma, T., Eozenou, P., Evans, D., Evans, T., Kieny, M.-P. and Wagstaff, A. (2014) Monitoring Progress towards Universal Health Coverage at Country and Global Levels. PLOS Medicine, 11, e1001731. https://doi.org/10.1371/journal.pmed.1001731

[3] Ministry of Labour, Immigration and Population, Department of Population (2015) The 2014 Myanmar Population and Housing Census. MLIP, Nay Pyi Taw. https://themimu.info/census-data

[4] The Lancet (2012) Burma: Health and Transition. The Lancet, 379, 2313. https://doi.org/10.1016/S0140-6736(12)60998-2 http://www.thelancet.com/journals/lancet/article/PIIS0140-6736(12)60998-2/fulltex $\mathrm{t}$

[5] Myint, P., Sein, T.T. and Cassels, A. (2015) What Are the Challenges Facing Myanmar in Progressing towards Universal Health Coverage? Asia Pacific Observatory on Health Systems and Policies. WHO, Geneva.

[6] Institute for Health Metrics and Evaluation (IHME) (2017) Myanmar. Seattle. http://www.healthdata.org/myanmar

[7] United Nations (2011) Political Declaration of the High-Level Meeting of the General Assembly on the Prevention and Control of Non-Communicable Diseases. A/RES/66/2. UN, New York.

[8] WHO (2017) "Best Buys" and Other Recommended Interventions for the Prevention and Control of Noncommunicable Disease. WHO, Geneva.

[9] WHO (2014) STEPwise Approach to Noncommunicable Disease Risk Factor Surveillance (STEPS). WHO, Geneva. http://www.who.int/chp/steps/en

[10] WHO (2014) STEPS Instrument (Core and Expanded). WHO, Geneva. http://www.who.int/chp/steps/instrument/STEPS_Instrument_V3.1.pdf?ua=1

[11] WHO (2011) Regional Office for South-East Asia (SEARO). Noncommunicable Disease Risk Factor Survey Myanmar 2009. WHO, New Delhi.

[12] WHO (2011) Global Adult Tobacco Survey (GATS). http://www.who.int/tobacco/surveillance/survey/gats/en

[13] Ministry of Health (2015) Report on National Survey of Diabetes Mellitus and Risk Factors for Non Communicable Diseases in Myanmar in 2014. Ministry of Health, Nay Pyi Taw.

[14] WHO (2010) Global Recommendations on Physical Activity for Health. WHO, Geneva.

[15] WHO Expert Consultation (2004) Appropriate Body-Mass Index for Asian Populations and Its Implications for Policy and Intervention Strategies. The Lancet, 363, 157-163. https://doi.org/10.1016/S0140-6736(03)15268-3

[16] Institute for Health Metrics and Evaluation (2017) Global Burden of Disease Study 2016 (GBD 2016). IHME, Seattle. http://ghdx.healthdata.org/gbd-2016

[17] National Health Network (2016) A Roadmap towards Universal Health Coverage in Myanmar (2016-2030).

http://www.3mdg.org/sites/3mdg.org/files/publication_docs/programme_of_health _reforms_-_version_1_0_-_2016_03_29.pdf 
[18] Boerma, T., AbouZahr, C., Evans, D. and Evans, T. (2014) Monitoring Intervention Coverage in the Context of Universal Health Coverage. PLOS Medicine, 11, e1001728. https://doi.org/10.1371/journal.pmed.1001728

[19] Clarke, C. (2017) Non-Communicable Diseases Kill 8.5 Million People in Asia Each Year. We Need a Plan to Fight Them. World Economic Forum.

https://www.weforum.org/agenda/2017/05/non-communicable-diseases-kill-8-5-mi lion-people-in-asia-each-year-we-need-a-plan-to-fight-them

[20] Deloitte (2015) A Perspective of Future Healthcare Landscape in ASEAN and Singapore.

https://www2.deloitte.com/content/dam/Deloitte/sg/Documents/risk/sea-risk-futur e-healthcare-thought-leadership-noexp.pdf

[21] WHO (2015) WHO Health Accounts. http://apps.who.int/nha/database/ViewData/Indicators/en

[22] Strengthening Public Health Capacity to Response to Myanmar Disease Transition. http://sphcmyanmar.org

[23] Knodel, J. and Nguyen, M.D. (2015) Grandparents and Grandchildren: Care and Support in Myanmar, Thailand and Vietnam. Ageing Society, 35, 1960-1988. https://doi.org/10.1017/S0144686X14000786

[24] Knodel, J., Pothisiri, W., Milintangul, C. and Bangkaew, B. (2015) Leaving Children with Grandparents in Myanmar: Experiences and Perceptions of Migrants in Samut Sakhon Province in Thailand. University of Michigan, Ann Arbor. 


\section{Appendix-Supplementary Tables}

Table A1. Socio-demographic characteristics, by age groups-WHO 2009 and 2014.

\begin{tabular}{ccccccccccccc}
\hline & \multicolumn{9}{c}{2009} & \multicolumn{1}{c}{2014} \\
\hline \multirow{2}{*}{ Sample } & & $15-24$ & $25-34$ & $35-44$ & $45-54$ & $55-64$ & Total & $25-34$ & $35-44$ & $45-54$ & $55-64$ & Total \\
\hline \multirow{2}{*}{ Sex (\%) } & $\mathrm{n}$ & 1015 & 1624 & 1829 & 1706 & 1255 & 7429 & 1810 & 2426 & 2491 & 2030 & 8757 \\
& Female & 13.1 & 22.0 & 25.7 & 23.0 & 16.2 & 100 & 20.3 & 28.7 & 28.3 & 22.6 & 100 \\
& Male & 14.5 & 21.6 & 23.0 & 22.9 & 18.0 & 100 & 21.3 & 25.9 & 28.6 & 24.2 & 100 \\
\hline \multirow{2}{*}{ Education (in years) } & Mean, Female & 8.8 & 7.6 & 7.0 & 5.8 & 4.8 & 6.7 & 6.5 & 5.9 & 5.1 & 4.5 & 5.5 \\
& Mean, Male & 9.3 & 8.1 & 8.0 & 7.3 & 6.1 & 7.7 & 6.9 & 5.9 & 6.0 & 5.9 & 6.2 \\
\hline \multirow{3}{*}{ Marital status (\%) } & Never & 71.0 & 25.1 & 13.1 & 10.5 & 6.6 & 21.9 & 24.4 & 11.6 & 8.1 & 6.9 & 12.2 \\
& Currently & 28.2 & 71.6 & 81.4 & 77.0 & 71.9 & 69.4 & 71.7 & 81.1 & 79.4 & 69.1 & 75.9 \\
& Other & 0.9 & 3.4 & 5.5 & 12.5 & 21.5 & 8.7 & 3.9 & 7.2 & 12.4 & 24.1 & 11.9 \\
\hline
\end{tabular}

Table A2. Current tobacco users (smoked and smokeless) as a percent (\%) for females and males, by age groups-WHO 2009 and 2014 .

\begin{tabular}{|c|c|c|c|c|c|c|c|c|c|c|c|c|}
\hline & & \multicolumn{6}{|c|}{2009} & \multicolumn{5}{|c|}{2014} \\
\hline & & $15-24$ & $25-34$ & $35-44$ & $45-54$ & $55-64$ & Total & $25-34$ & $35-44$ & $45-54$ & $55-64$ & Total \\
\hline \multirow{3}{*}{ Current smokers (\%) } & Female & 1.0 & 3.3 & 6.2 & 11.6 & 16.8 & 7.8 & 1.7 & 5.6 & 13.0 & 21.4 & 8.4 \\
\hline & Male & 34.7 & 47.5 & 44.5 & 49.5 & 44.0 & 44.8 & 41.4 & 45.7 & 45.1 & 43.7 & 43.8 \\
\hline & Total & 14.7 & 20.0 & 19.9 & 26.1 & 27.9 & 22.0 & 21.6 & 25.7 & 29.0 & 32.5 & 26.1 \\
\hline \multirow{3}{*}{$\begin{array}{l}\text { Current smokeless } \\
\text { tobacco users }(\%)\end{array}$} & Female & 5.3 & 11.9 & 18.9 & 21.1 & 19.2 & 16.1 & 17.1 & 28.3 & 30.0 & 24.2 & 24.1 \\
\hline & Male & 45.0 & 63.0 & 54.3 & 49.6 & 41.6 & 51.4 & 66.3 & 69.5 & 58.6 & 45.7 & 62.2 \\
\hline & Total & 21.5 & 31.3 & 31.5 & 32.1 & 28.4 & 29.7 & 41.8 & 48.9 & 44.3 & 34.9 & 43.2 \\
\hline
\end{tabular}

Table A3. Percentage (\%) current drinkers and consuming less than recommended five servings of fruit/vegetables per day, for females and males, by age group-WHO 2009 and 2014.

\begin{tabular}{|c|c|c|c|c|c|c|c|c|c|c|c|c|}
\hline & & \multicolumn{6}{|c|}{2009} & \multicolumn{5}{|c|}{2014} \\
\hline & & $15-24$ & $25-34$ & $35-44$ & $45-54$ & $55-64$ & Total & $25-34$ & $35-44$ & $45-54$ & $55-64$ & Total \\
\hline \multirow{6}{*}{$\begin{array}{c}\text { Current } \\
\text { drinker } \\
(\%)^{*}\end{array}$} & Female & 1.3 & 1.7 & 2.1 & 1.2 & 0.8 & 1.5 & 2.2 & 1.4 & 1.3 & 0.5 & 1.5 \\
\hline & $95 \% \mathrm{CI}$ & $0.4-4.2$ & $0.8-3.6$ & $1.1-3.8$ & $0.6-2.5$ & $0.3-1.8$ & $0.8-2.8$ & $1.1-3.3$ & $0.5-2.2$ & $01 .-2.5$ & $0.0-1.3$ & $0.7-2.3$ \\
\hline & Male & 23.7 & 43.8 & 36.4 & 28.5 & 18.9 & 31.2 & 47.8 & 42.3 & 32.5 & 17.1 & 38.1 \\
\hline & $95 \% \mathrm{CI}$ & $19.2-28.9$ & $39.8-47.8$ & $33.4-39.5$ & $24.4-33.0$ & $15.3-23.1$ & $28.6-33.8$ & $40.9-54.7$ & $35.5-49.1$ & $26.1-39.0$ & $10.8-23.4$ & $33.9-42.2$ \\
\hline & Total & 10.4 & 17.6 & 14.4 & 11.7 & 8.2 & 12.9 & 25.1 & 21.9 & 16.9 & 8.8 & 19.8 \\
\hline & $95 \% \mathrm{CI}$ & $8.3-12.9$ & $15.3-20.2$ & $12.8-16.1$ & $9.8-13.8$ & $6.7-10.0$ & $11.7-14.2$ & $20.3-29.9$ & $18.4-25.3$ & $12.9-20.8$ & $5.6-12.0$ & $16.8-22.8$ \\
\hline \multirow{6}{*}{$\begin{array}{c}\text { Diet low in } \\
\text { F/V (\%) }\end{array}$} & Female & 90.4 & 89.4 & 91.2 & 89.7 & 92.7 & 90.6 & 86.7 & 88.0 & 87.3 & 91.6 & 87.9 \\
\hline & $95 \% \mathrm{CI}$ & $87.4-92.7$ & 86.4 - 91.9 & $88.7-93.2$ & $86.9-92.0$ & $90.0-94.7$ & $88.7-92.2$ & $83.1-90.2$ & $84.7-91.3$ & $83.8-90.7$ & $88.6-94.6$ & $85.8-90.1$ \\
\hline & Male & 87.3 & 88.0 & 91.0 & 91.3 & 90.5 & 89.8 & 85.5 & 84.2 & 87.1 & 83.6 & 85.2 \\
\hline & $95 \% \mathrm{CI}$ & $83.2-90.5$ & $85.1-90.4$ & $88.3-93.2$ & $88.0-93.8$ & $86.6-93.3$ & $87.5-91.8$ & $80.6-90.4$ & $78.8-89.6$ & $82.5-91.6$ & $78.9-88.2$ & $82.0-88.3$ \\
\hline & Total & 89.1 & 88.9 & 91.1 & 90.4 & 91.8 & 90.3 & 86.1 & 86.1 & 87.2 & 87.6 & 86.6 \\
\hline & $95 \% \mathrm{CI}$ & $86.3-91.4$ & $86.5-90.9$ & $88.9-92.9$ & $87.8-92.4$ & $89.4-93.7$ & $88.4-91.9$ & $82.8-89.3$ & $82.7-89.5$ & $84.0-90.3$ & $84.9-90.3$ & $84.1-89.0$ \\
\hline
\end{tabular}

${ }^{*}$ In last 30 days. 
Table A4. Percentage (\%) undertaking low, moderate and high levels of physical activity for females and males, by age group-WHO 2009 and 2014.

\begin{tabular}{|c|c|c|c|c|c|c|c|c|c|c|c|c|}
\hline & & \multicolumn{6}{|c|}{2009} & \multicolumn{5}{|c|}{2014} \\
\hline $\begin{array}{l}\text { Level of } \\
\text { physical } \\
\text { activity }^{\star}\end{array}$ & & $15-24$ & $25-34$ & $35-44$ & $45-54$ & $55-64$ & Total & $25-34$ & $35-44$ & $45-54$ & $55-64$ & Total \\
\hline \multirow{4}{*}{ Low } & Female & 13.2 & 14.4 & 11.9 & 13.0 & 19.6 & 14.1 & 21.4 & 18.0 & 20.8 & 26.3 & 21.1 \\
\hline & $95 \% \mathrm{CI}$ & $10.5-16.5$ & $11.1-18.4$ & $9.3-15.0$ & $10.5-16.0$ & $15.9-24.0$ & $11.8-16.8$ & $17.3-25.6$ & $14.3-21.7$ & $15.9-25.8$ & $22.2-30.4$ & $17.9-24.4$ \\
\hline & Male & 5.8 & 8.1 & 11.7 & 11.2 & 14.5 & 10.4 & 11.4 & 13.3 & 15.4 & 20.6 & 14.3 \\
\hline & $95 \% \mathrm{CI}$ & $3.6-9.3$ & $5.6-11.4$ & $9.6-14.2$ & $8.5-14.6$ & $11.2-18.7$ & $8.9-12.3$ & $7.1-15.8$ & $8.8-17.7$ & $10.2-20.6$ & $14.1-27.1$ & $11.2-17.4$ \\
\hline \multirow{4}{*}{ Moderate } & Female & 37.0 & 30.2 & 30.9 & 32.0 & 35.6 & 32.6 & 18.7 & 20.8 & 17.8 & 28.5 & 20.6 \\
\hline & $95 \% \mathrm{CI}$ & $30.5-44.1$ & $25.2-35.8$ & $26.7-35.5$ & $27.8-36.4$ & $430.8-40.7$ & $28.8-36.6$ & $14.8-22.5$ & $17.6-24.1$ & $14.0-21.5$ & $23.9-33.1$ & $18.0-23.2$ \\
\hline & Male & 26.4 & 21.9 & 24.6 & 28.0 & 32.8 & 26.5 & 9.2 & 11.7 & 17.8 & 21.7 & 13.8 \\
\hline & $95 \% \mathrm{CI}$ & $22.6-30.6$ & $17.7-26.7$ & $20.9-28.7$ & $24.1-32.2$ & $27.7-38.2$ & $23.6-29.6$ & $5.8-12.6$ & $8.5-14.9$ & $13.6-22.0$ & $17.1-26.4$ & $11.5-16.1$ \\
\hline \multirow{4}{*}{ High } & Female & 49.8 & 55.4 & 57.2 & 55.1 & 44.8 & 53.3 & 59.9 & 61.2 & 61.4 & 45.2 & 58.2 \\
\hline & $95 \% \mathrm{CI}$ & $42.2-57.3$ & $48.6-62.0$ & $51.3-62.9$ & $49.4-60.6$ & $538.2-51.7$ & $47.9-58.7$ & $53.7-66.1$ & $55.6-66.7$ & $54.9-67.9$ & $41.2-49.2$ & $53.9-62.6$ \\
\hline & Male & 67.8 & 70.1 & 63.7 & 60.9 & 52.7 & 63.1 & 79.3 & 75.0 & 66.8 & 57.6 & 72.0 \\
\hline & $95 \% \mathrm{CI}$ & $63.1-72.3$ & $63.9-75.6$ & $58.7-68.5$ & $55.6-65.9$ & $46.7-58.7$ & $59.1-66.8$ & $72.9-85.7$ & $69.1-80.9$ & $59.7-74.0$ & $50.7-64.5$ & $67.9-76.0$ \\
\hline
\end{tabular}

${ }^{\star}$ Low $=$ defined as $<600$ MET-minutes/week; Moderate= not meeting criteria for low or high; High = defined as $\geq 3000 \mathrm{MET}$-minutes/week $(\mathrm{WHO} 2010)$.

Table A5. Percentage (\%) of females and males with high blood pressure by medication treatment status, by age group-WHO 2009 and 2014.

\begin{tabular}{|c|c|c|c|c|c|c|c|c|c|c|c|c|}
\hline & & \multicolumn{6}{|c|}{2009} & \multicolumn{5}{|c|}{2014} \\
\hline & & $15-24$ & $25-34$ & $35-44$ & $45-54$ & $55-64$ & Total & $25-34$ & $35-44$ & $45-54$ & $55-64$ & Total \\
\hline $\begin{array}{l}\text { High BP, excluding } \\
\text { those on meds }\end{array}$ & Male & 13.3 & 17.6 & 29.7 & 34 & 46.3 & 28.4 & 12.2 & 22 & 31.7 & 38.9 & 23.4 \\
\hline \multirow{2}{*}{$\begin{array}{l}\text { High BP, including } \\
\text { those on meds }\end{array}$} & Female & 8.0 & 14.8 & 28.5 & 39.7 & 53.2 & 29.3 & 11.7 & 30.7 & 37.9 & 45.3 & 28 \\
\hline & Male & 14.4 & 18.1 & 31.8 & 37.1 & 51 & 31 & 12.3 & 23 & 33.8 & 41.1 & 24.7 \\
\hline
\end{tabular}

High blood pressure $(\mathrm{BP})=$ systolic blood pressure $(\mathrm{SBP}) \geq 140$ and/or diastolic blood pressure $(\mathrm{DBP}) \geq 90 \mathrm{mmHg}$.

Table A6. Percentage (\%) of respondents categorized by body mass index, by sex and age group - WHO 2009 and 2014.

\begin{tabular}{|c|c|c|c|c|c|c|c|c|c|c|c|c|}
\hline & & \multicolumn{6}{|c|}{2009} & \multicolumn{5}{|c|}{2014} \\
\hline & & $15-24$ & $25-34$ & $35-44$ & $45-54$ & $55-64$ & Total & $25-34$ & $35-44$ & $45-54$ & $55-64$ & Total \\
\hline \multirow{3}{*}{ Underweight } & & $24.4-33.7$ & $15.3-21.1$ & $7.8-11.7$ & $11.7-16.7$ & $14.8-23.5$ & $14.7-18.4$ & $15.4-24.2$ & $7.5-12.8$ & $9.2-14.4$ & $14.9-22.4$ & $12.8-17.6$ \\
\hline & Male & 24.4 & 22.6 & 16.5 & 16.3 & 21.5 & 19.8 & 21.4 & 14.9 & 21.4 & 19.1 & 19.2 \\
\hline & & $19.9-29.6$ & $19.0-26.8$ & $13.6-19.8$ & $13.1-20.1$ & $17.7-25.7$ & $17.3-22.6$ & $15.4-27.4$ & $10.8-19.0$ & $17.0-25.8$ & $14.0-24.1$ & $15.6-22.7$ \\
\hline \multirow{3}{*}{ Normal } & Female & 61.4 & 58.6 & 52.6 & 46.3 & 49.7 & 53.2 & 59.2 & 54.1 & 49.5 & 49.5 & 54.0 \\
\hline & & $56.5-66.2$ & $55.9-61.2$ & $49.5-55.8$ & $42.9-49.7$ & $44.7-54.6$ & $51.1-55.2$ & $54.5-63.9$ & $49.4-58.7$ & $46.8-52.3$ & $45.3-53.7$ & $51.5-56.6$ \\
\hline & Male & 68.1 & 63.8 & 61.6 & 60.5 & 59.9 & 62.5 & 69.3 & 70.6 & 59.1 & 64.9 & 66.7 \\
\hline
\end{tabular}




\section{Continued}

\begin{tabular}{|c|c|c|c|c|c|c|c|c|c|c|c|c|}
\hline \multirow{4}{*}{ Overweight } & Female & 8.4 & 16.8 & 27.9 & 28.2 & 21.9 & 22.0 & 16.0 & 27.0 & 26.4 & 22.3 & 22.4 \\
\hline & & $6.2-11.3$ & $14.1-19.8$ & $25.3-30.8$ & $24.9-31.9$ & $18.3-26.0$ & $20.2-23.9$ & $12.5-19.6$ & $23.6-30.5$ & $22.5-30.3$ & $18.1-26.5$ & $20.1-24.7$ \\
\hline & Male & 4.8 & 11.2 & 17.6 & 17.6 & 12.6 & 13.5 & 7.5 & 12.4 & 15.6 & 12.5 & 11.5 \\
\hline & & $3.1-7.3$ & $8.5-14.7$ & $14.4-21.3$ & $14.5-21.1$ & $10.1-15.7$ & $11.9-15.2$ & $5.1-9.9$ & $8.2-16.6$ & $11.3-19.8$ & $7.9-17.1$ & $9.4-13.6$ \\
\hline \multirow{4}{*}{ Obese } & Female & 1.3 & 6.6 & 9.9 & 11.5 & 9.7 & 8.4 & 5.0 & 8.8 & 12.2 & 9.5 & 8.4 \\
\hline & \multirow{3}{*}{ Male } & $0.7-2.6$ & $5.0-8.6$ & $8.0-12.2$ & $9.1-14.4$ & $7.4-12.7$ & $7.0-9.9$ & $3.2-6.7$ & $6.9-10.6$ & $8.2-16.2$ & $6.4-12.6$ & $6.6-10.1$ \\
\hline & & 2.7 & 2.3 & 4.3 & 5.7 & 6.0 & 4.3 & 1.8 & 2.1 & 4.0 & 3.5 & 2.6 \\
\hline & & $1.4-5.2$ & $1.2-4.6$ & $2.8-6.5$ & $3.7-8.6$ & $3.9-9.2$ & $2.9-6.2$ & $0.3-3.2$ & $0.8-3.5$ & $2.1-5.8$ & $1.7-5.3$ & $1.8-3.5$ \\
\hline
\end{tabular}

Note: Underweight $\left(\right.$ BMI $\left.<18.5 \mathrm{~kg} / \mathrm{m}^{2}\right)$, Normal (BMI $\left.18.5-24.9 \mathrm{~kg} / \mathrm{m}^{2}\right)$, overweight $\left(\mathrm{BMI} \geq 25 \mathrm{~kg} / \mathrm{m}^{2}\right)$, obese $\left(\mathrm{BMI} \geq 30 \mathrm{~kg} / \mathrm{m}^{2}\right)$.

Table A7. Percentage (\%) of females and males with diabetes assessments, by age group WHO 2009 and 2014.

\begin{tabular}{|c|c|c|c|c|c|c|c|c|c|c|c|c|}
\hline & & \multicolumn{6}{|c|}{2009} & \multicolumn{5}{|c|}{2014} \\
\hline & & $15-24$ & $25-34$ & $35-44$ & $45-54$ & $55-64$ & Total & $25-34$ & $35-44$ & $45-54$ & $55-64$ & Total \\
\hline \multirow{3}{*}{$\begin{array}{l}\text { Diabetes, } \\
\text { Female }\end{array}$} & Never tested & 95.7 & 87.2 & 82.5 & 80.6 & 74.5 & 83.5 & 91.1 & 84.2 & 75.5 & 70.0 & 82.4 \\
\hline & Measured, not $\mathrm{Dx}^{*}$ & 4.0 & 12.1 & 15.8 & 16.3 & 21.2 & 14.4 & 8.1 & 13.0 & 17.2 & 17.7 & 13.0 \\
\hline & $\mathrm{Dx}$ & 0.4 & 0.7 & 1.8 & 3.1 & 4.3 & 2.1 & 0.8 & 2.7 & 7.3 & 12.3 & 4.6 \\
\hline \multirow{3}{*}{$\begin{array}{l}\text { Diabetes, } \\
\text { Male }\end{array}$} & Never tested & 96.9 & 90.3 & 84.6 & 81.9 & 77.2 & 85.6 & 94.3 & 91.4 & 84.6 & 80.0 & 89.1 \\
\hline & Measured, not Dx & 3.1 & 9.8 & 13.4 & 16.3 & 18.8 & 12.8 & 5.5 & 6.6 & 9.6 & 15.8 & 8.3 \\
\hline & Dx & 0.0 & 0.0 & 2.0 & 1.8 & 4.1 & 1.6 & 0.2 & 2 & 5.9 & 4.2 & 2.5 \\
\hline
\end{tabular}

${ }^{\star} \mathrm{Dx}=$ diagnosed. Measured, not $\mathrm{Dx}=$ blood glucose assessed with a negative result. 